with holes three-fourths of an inch in diameter. The flasks are kept in this rack in the laboratory. The table thus serves not only as an excellent drying rack, but also as a safe place to prevent breaking.

\title{
AN EXPERIMENT ILLUSTRATING THE LAW OF MULTIPLE PROPORTIONS.
}

\author{
BY WARREN RUFUS SMITH.
}

Department of Chemistry, Levis Institute, Chicago.

The advantage of illustrating the fundamental laws of chemistry by simple quantitative experiments in the laboratory is now generally recognized. In the case of most of these laws suitable experiments are easily devised; and satisfactory directions can be found in any modern laboratory manual. In the case of the law of multiple proportions, however, the majority of the suggestions for demonstrating the fact that "when two substances react in more than one proportion, the quantities of one that react with a given quantity of the other, bear a simple ration to each other" are either inexact or difficult of manipulation; or else they deal with substances with which the ordinary student is unfamiliar. Some time ago I devised an experiment which avoids these difficulties to a degree, and which, so far as I know, has not hitherto been published in any text-book or periodical.* have used this experiment with good success in both academic and collegiate classes, and it has found favor in at least one laboratory other than my own. The directions are as follows:

Sodium carbonate and hydrochloric acid react in two different ways. The end reaction in one case may be apparent by using methyl orange as an indicator; in the other case by using phenolphthalein. Familiarize yotrself with the colors given by methyl orange in acids and alkalies.

Put about roo cc. water into a beaker. Add a few drops of methyl orange solution. Run in from a burette a known quantity of sodium carbonate solution. Titrate with hydrochloric acid. Add the hydrochloric acid slowly toward the end, keeping the solution well stirred. Repeat this

* An outline of this experiment is given in Congdon's Laboratory Instructions in chemistry, page $95 .-$ Editor. 
work until you get two results that correspond with each other. Arrange the results as in the preceding experiment.

Then repeat this work, using phenolphthalein in the place of methyl orange. The hydrochloric acid must be added very cautiously, keeping the solution well stirred so as to avoid effervescence. Arrange results as before.

Are the amounts of acid that react with a given quantity of sodium carbonate the same in the two cases? If not, is there any simple ratio between them?

This experiment has immediately followed one illustrating: the law of definite propontions, by the titration of acid with alkali, using phenolphthalein as an indica tor so that the directions for manipulation are not as full as would otherwise be needful. The stock solutions are approximately normal. Students have obtained better results by working with solutions of this strength and diluting in the beaker than by using more dilute solutions directly.

A variation of the above experiment is to dissolve an indefinite amount of sodium carbonate in the beaker, add both indicators and titrate with acid. This method does not give as exact results in the hands of students, but, on the other hand, it is simpler, and the principle involved is more easily grasped.

\section{TWO SIMPLE AND CONVENIENT GAS GENERATORS.}

\section{BY C. E. LINEBARGER.}

I. The form of gas generator commonly used by students in elementary chemistry consists of a bottle or flask fitted with a twohole stopper through which pass a delivery tube and a funnel or "thistle" tube. While such a generator is simple and inexpensive, it does not give a very regular flow of gas, and the "thistle" tube is rather fragile. The substitution of a stopcock funnel for the "thistle" tube makes the apparatus, however, all that cotild be desired. But stopcock funnels are too expensive for general use in the laboratory. Still one can be readily improvised by the student from his stock of apparatus, which answers very well.

A bit of rubber tubing about a centimeter long and of such a size as to fit rather snugly in the neck of the funnel, has a hole about a millimeter in diameter cut in its side near one end. (Fig. 